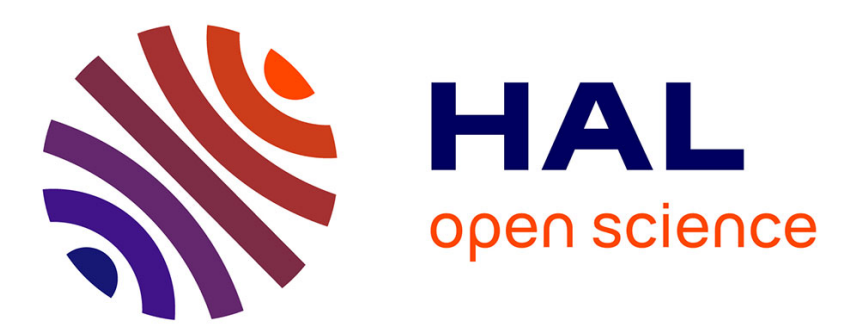

\title{
A novel method determining longitudinally induced magnetic anisotropy in amorphous and nanocrystalline soft materials
}

Frédéric Mazaleyrat, Zs Gercsi, Michel Lécrivain, L. K. Varga

\section{- To cite this version:}

Frédéric Mazaleyrat, Zs Gercsi, Michel Lécrivain, L. K. Varga. A novel method determining longitudinally induced magnetic anisotropy in amorphous and nanocrystalline soft materials. Journal of Magnetism and Magnetic Materials, 2004, 280 (2-3), pp.391-394. 10.1016/j.jmmm.2004.01.098 . hal-01496935

\section{HAL Id: hal-01496935 \\ https://hal.science/hal-01496935}

Submitted on 5 Apr 2017

HAL is a multi-disciplinary open access archive for the deposit and dissemination of scientific research documents, whether they are published or not. The documents may come from teaching and research institutions in France or abroad, or from public or private research centers.
L'archive ouverte pluridisciplinaire HAL, est destinée au dépôt et à la diffusion de documents scientifiques de niveau recherche, publiés ou non, émanant des établissements d'enseignement et de recherche français ou étrangers, des laboratoires publics ou privés. 


\title{
A novel method determining longitudinally induced magnetic anisotropy in amorphous and nanocrystalline soft materials
}

\author{
F. Mazaleyrat,* Zs. Gercsi, and M. Lécrivain
}

SATIE, ENS de Cachan, 61, avenue du Président Wilson 94235 Cachan cedex, France

\author{
L.K. Varga \\ RISSPO, Hungarian Academy of Science, \\ POBox 49, 1525 Budapest, Hungary
}

(Dated: 20 May 2003)

\begin{abstract}
In ferromagnetic amorphous and nanocrystalline soft magnetic alloys the induced magnetic anisotropy plays a fundamental role in the hysteresis behavior but, due to the elongated shape, it can be measured only if $K_{U}$ is perpandicular to the sample long axis. In order to measure the longitudinal induced anisotropy, an original method derive from known thin layers measurement techniques was used. Hysteresis loops shifted by perpendicular bias field were recorded for this purpose. Direct measurement of the longitudinal induced anisotropy in amorphous and nanocrystalline ribbons or wire without needing sample preparation is reported for the first time. Evidence of self-induced anisotropy is brought in a Fe-Co based nanocrystalline alloy.
\end{abstract}

*Electronic address: mazaleyrat@satie.ens-cachan.fr; URL: http://www.satie.ens-cachan.fr 
In the early years after the discovery of Finemet, various experiment have been conducted in the aim of inducing uniaxial anisotropy $\left(K_{U}\right)$ in nanocrystalline alloys. As it was expected from previous experiments with amorphous materials, uniaxial magnetic anisotropy were successfully induced in the direction of the field applied during nanocrystallization [1]. Herzer has shown that this phenomenon is related to the Fe-Si pair ordering during the crystallization stage [2]. The possibility of inducing anisotropy in Finemet by stress annealing was first attested by Glaser [3] and was proved to be transversal and strikingly strong. This last method can yield both transversal (positive) or longitudinal (negative) depending of magnetic and mechanical properties of both phases [4].

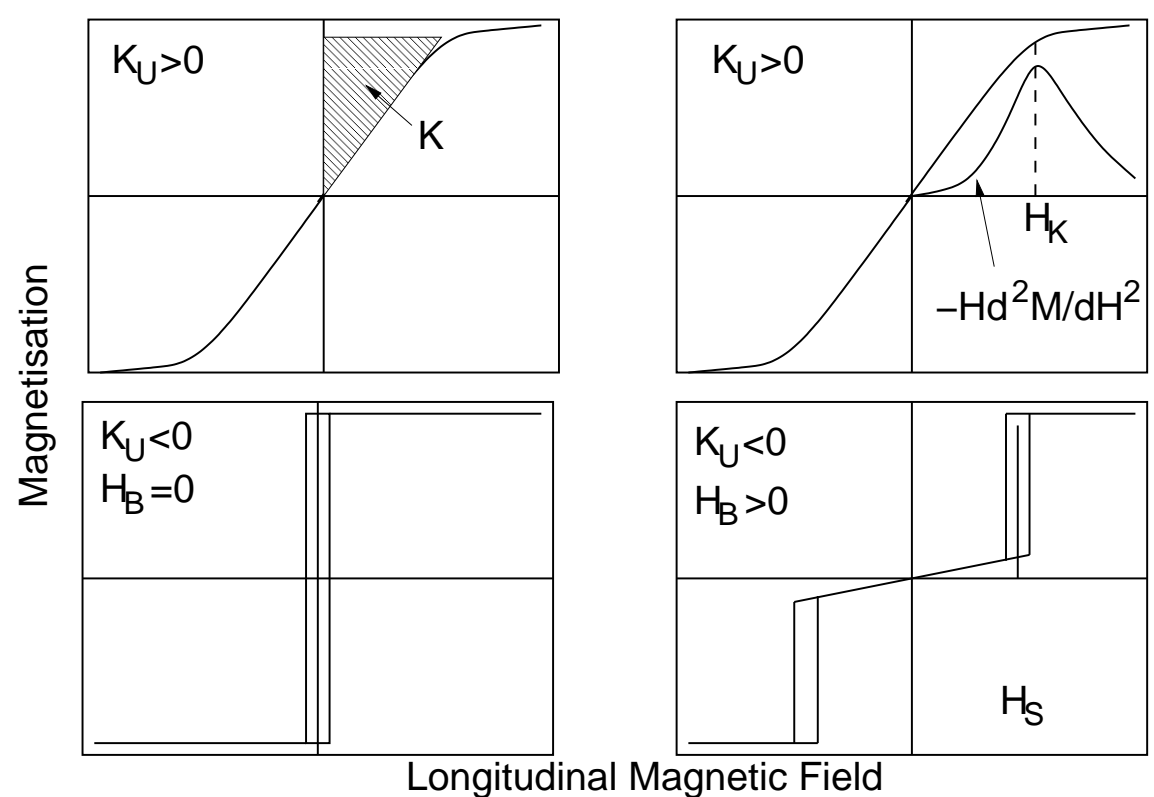

Figure 1: Various methods to determine uniaxial induced anisotropy

The transversal induced anisotropy can be evaluated by two different techniques. If the hysteresis loop is linear up to saturation, the magnetization occurs by rotation only and $K_{U}$ can be easily deduced from the area on the left of the loop as depicted in Fig. 1 (top left box). However a more general method consisting in the computation of the second derivative of the return branch of the hysteresis loop was proposed in [5] and multiplying by the field yields the distribution of anisotropy fields [6] (see Fig. 1 top right box). The same result can be obtained in amore accurate way by a second harmonic detection induced by a small ac field superimposed to the dc field [7]. In the case of longitudinal induced anisotropy, the square hysteresis loop is clearly unsuitable for these evaluations because the magnetization reversal 
Table I: Anisotropy fields measured by the present technique (except for $K_{U}>0$ )

\begin{tabular}{ccccccc}
\hline Material & Sample & Annealing & $\mathrm{H}_{\mathrm{k}}(\mathrm{A} / \mathrm{m})$ & $\mu_{0} \mathrm{M}_{\mathrm{s}}(\mathrm{T})$ & $\mathrm{K}_{\mathrm{u}}\left(\mathrm{J} / \mathrm{m}^{3}\right)$ & $\mathrm{H}_{c}(\mathrm{~A} / \mathrm{m})$ \\
\hline \hline $\mathrm{Fe}_{77.5} \mathrm{~B}_{15} \mathrm{Si}_{7.5}$ & $\mathrm{~A}$ & As-cast & $-44 \pm 3$ & 1.57 & $-35 \pm 2$ & 19 \\
$\mathrm{Fe}_{73.5} \mathrm{Si}_{13.5} \mathrm{~B}_{9} \mathrm{Nb}_{3} \mathrm{Cu}_{1}$ & $\mathrm{~F}$ & Long. $\mathrm{H}-550^{\circ} \mathrm{C} / 1 \mathrm{~h}$ & $-66 \pm 5$ & 1.24 & $-41 \pm 3$ & 5.5 \\
$\left(\mathrm{Fe}_{90} \mathrm{Co}_{10}\right)_{73.5} \mathrm{Si}_{13.5} \mathrm{~B}_{9} \mathrm{Nb}_{3} \mathrm{Cu}_{1}$ & $\mathrm{C}$ & $550^{\circ} \mathrm{C} / 1 \mathrm{~h}$ & $-68 \pm 3$ & 1.16 & $-40 \pm 2$ & 8.4 \\
$\left(\mathrm{Fe}_{90} \mathrm{Co}_{10}\right)_{73.5} \mathrm{Si}_{13.5} \mathrm{~B}_{9} \mathrm{Nb}_{3} \mathrm{Cu}_{1}$ & $\mathrm{C}_{\mathrm{L}}$ & Long. $\mathrm{H}-550^{\circ} \mathrm{C} / 1 \mathrm{~h}$ & $-158 \pm 2$ & 1.16 & $-92 \pm 1$ & 8 \\
$\left(\mathrm{Fe}_{90} \mathrm{Co}_{10}\right)_{73.5} \mathrm{Si}_{13.5} \mathrm{~B}_{9} \mathrm{Nb}_{3} \mathrm{Cu}_{1}$ & $\mathrm{C}_{\mathrm{T}}$ & Trans. $\mathrm{H}-550^{\circ} \mathrm{C} / 1 \mathrm{~h}$ & $+86 \pm 3$ & 1.16 & $+50 \pm 2$ & 5.8 \\
$\mathrm{Fe}_{90} \mathrm{Zr}_{7} \mathrm{~B}_{3}$ & $\mathrm{~N}_{\mathrm{S}}$ & Stress-600 & & \\
& & & & & & \\
\end{tabular}

takes place by a single large Barkhausen jump at $\pm H_{C}$. The coercive force in this case corresponds to the domain wall nucleation energy which is indirectly linked to $K_{U}$ through the domain wall energy. However many other parameters are involved and finally $K_{U}$ cannot be deduced from $H_{C}$. The torque method as well as bi-axial magnetic measurement can be applied but both requires circular samples which are difficult to cut from brittle ribbons. In addition, these methods are very sensitive to the shape of the sample. For this purpose, a method originally proposed by Weber et al.[8] have been adapted to long samples without needing sample preparation. The sweeping field $(H)$ is applied along the easy axis which is longitudinal in this case. The hysteresis loop is obtained by integration of the pick-up coil voltage within the same axis. If a transversal bias field $H_{B}$ larger than the anisotropy field $H_{K}$ is applied, the hysteresis loop is flattened and pratically anhysteretic until a critical value of $H$ is reached at which the magnetization switch is shifted at $H_{S} \pm H_{C}$ (see Fig. 1).

The total magnetic energy depends on the angle $\varphi$ between the magnetization and the measurement direction for a given angle $\theta$ between the easy axis and the measurement direction. When two perpendicular fields are applied and the easy axis is parallel to the measurement direction $(\theta=0)$, we have:

$$
E(\varphi)=K_{U} \sin ^{2} \varphi-\mu_{0} M_{S} H \cos \varphi-\mu_{0} M_{S} H_{\perp} \sin \varphi
$$

In this case, there is 3 stable positions of the magnetization $\varphi=0$ and $\varphi= \pm \pi / 2$ and the magnetization switches from one position to another (at $H=H_{S}$ ) when :

$$
E(0)=-\mu_{0} M_{S} H=E(\pi / 2)=K_{U}-\mu_{0} M_{S} H_{\perp}
$$


For a constant $H_{\perp}, E(0)=E(\pi / 2)$ so the anisotropy constant is: $K_{U}=\mu_{0} M_{S}\left(H_{S}-H_{\perp}\right)$ and the anisotropy field is:

$$
H_{K}=2\left(H_{S}-H_{\perp}\right)
$$

For circular samples with in-plane applied fields, $K_{U}$ is deduced from a single split hysteresis loop because the demagnetizing factors are equal in both direction $\left(N_{\|}=N_{\perp}\right)$, so $H_{K}$ comes from eq. (2). In the case of long samples the longitudinal field is the applied one because of the negligible demagnetizing effect, but the perpendicular inner field is much smaller than the applied biasing field: $H_{\perp}=H_{B}-N_{\perp} M_{\perp}$. The magnetization can be substituted if the field is smaller or equal to the switching field: as there is no domain, permeability is basically due to a rotational magnetization process and thus depends linearly on the field: $M_{\perp}=\chi H_{B}$, so

$$
H_{K}=2\left[H_{S}-\left(1-N_{\perp} \chi\right) H_{B}\right]=2\left(H_{S}-\alpha H_{B}\right)
$$

Of course the parameter $\alpha$ is highly dependent on the the demagnetizing factor which cannot be determined for most of samples with sufficient accuracy. This difficulty is evaded by using a plotting strategy: several hysteresis loops are recorded with various values of the biasing field. The linear plot of $H_{S}$ as a function of $H_{B}$ allows the determination of $H_{K}$ by extrapolation at $H_{B}=0 \Rightarrow H_{K}=2 H_{S}(0)$.

The experimental set-up, is composed of a $0.52 \mathrm{~m}$ long solenoid generating the longitudinal sweeping field in the homogeneous part of which the $7 \mathrm{~cm}$ long pick up coil and the sample are positioned and a perpendicular $0.3 \mathrm{~m}$ in diameter Helmholtz coils set. In our case this coils set is about $35 \mathrm{~kg}$ and $H_{B}\left(20 \mathrm{kAm}^{-1}\right)$ is sufficient only for the amorphous wire sample. Another set-up can pass through the deficient field problem, using an arrangement composed of two perpendicular iron cores. This device was already used for magnetostriction measurements by small angle magnetization rotation method [9]. The longitudinal field is known from Ampère's theorem, because $N_{\|}$is strictly zero. In the other hand, the perpendicular field depends strongly on the position of the ribbon in the gap. This field is in a given position is $H_{\perp}=\sigma n I_{B} / d$, where $\sigma$ is Hopkinson's leakage coefficient, if the yoke is far from saturation. Equation 3 becomes $H_{K}=2\left(H_{S}-\alpha^{\prime} I_{B}\right)$, where $\alpha^{\prime}$ is eliminated by the plotting strategy.

Different type of nanocrystalline alloys were produced and annealed with or without longitudinal $\left(800 \mathrm{~A} . \mathrm{m}^{-1}\right)$ and/or transverse $\left(10 \mathrm{kA} . \mathrm{m}^{-1}\right)$ fields or under a $100 \mathrm{MPa}$ stress 
according to Table I. A first important point is to verify the independence of $H_{S}$ upon the maximum sweeping field $H_{\max }$ in particular is the sample is not fully saturated. For this purpose, several loops were recorded with a constant $H_{B}$ and varying $H_{\max }$. $H_{S}$ was proved to be independent of $H_{\max }$ if the latter is sufficient to occur the switching of the magnetization. The relevance of this is illustrated in Fig. 2 where it is visible that the samples are not saturated for the largest bias fields. From these split loops, the values of $H_{S}$ are extracted and plotted as a function of $H_{B}$ in Fig. 3. The perfect alignment of points allows an accurate extrapolation to zero which give the values of $H_{K}$ by a least means square linear fit with a remarkably low standard deviation. Table I summarizes the $\mathrm{H}_{\mathrm{k}}$ and $\mathrm{K}_{\mathrm{u}}$ values of selected materials.

The anisotropy associated to the single longitudinal core domain of amorphous $\mathrm{Fe}_{77.5} \mathrm{~B}_{15} \mathrm{Si}_{7.5}$ was measured with the present method. The result is a quite low value compared to the perpendicular anisotropy associated with the shell suggesting a quite small quenched-in tensile stress in the core $(\sim 2 \mathrm{MPa})$. The stress annealed Nanoperm alloy $\left(\mathrm{N}_{\mathrm{S}}\right)$ exhibits a $-150 \mathrm{~J} / \mathrm{m}^{3}$ anisotropy only which is very low compared to Finemet $\left(\sim+1000 \mathrm{~J} / \mathrm{m}^{3}\right)$ annealed in the same conditions. This result suggest a weaker back-stress effect and open new investigation fields on stress induce anisotropy. Concerning the field annealed materials, the $\mathrm{F}_{\mathrm{L}}$ sample exhibits a slightly higher value of $K_{U}$ compared to transversal field annealing (10-20 J/ $\mathrm{m}^{3}$ ) [10], which can be explained by a shape contribution. In contrast, relatively large $K_{U}$ were induced in the Co doped alloy $\left(\mathrm{C}_{\mathrm{L}} \& \mathrm{C}_{\mathrm{T}}\right)$ as previously reported [11]. The fact that, in the longitudinal $\left(\mathrm{C}_{\mathrm{L}}\right)$ and transversal $\left(\mathrm{C}_{\mathrm{T}}\right)$ field annealed samples have not the same value of $K_{U}$ (by opposite sign) may be explained partly by shape effect but also by the insufficient inner transversal field during annealing of $\mathrm{C}_{\mathrm{T}}$ sample due to the demagnetizing factor $\left(N_{\perp} \gg N_{\|}\right)$. A surprising effect is the splitting of the hysteresis loop of Co-doped sample annealed without field showing a notable long range uniaxial anisotropy comparable to that of $\mathrm{F}_{\mathrm{L}}$ sample. This "self-induced" anisotropy is of great importance in the theory of random anisotropy model proposed by Suzuki et al. [12]. Indeed the change from the classical $D^{6}$ dependence of the coercive field to a $D^{3}$ law for some alloys (e.g. Nanoperm) was explained by the introduction of a long range $K_{U}$ in the model which existence was never experimentally demonstrated. The origin of this self-induced anisotropy is not clear at all but two explanations are possible. A first one would involve the magneto-elastic origin linked to the different thermal dilatation coefficients of both amorphous and crystalline 
phases but it should be a priori a short range contribution subject to averaging out. Another explanations should be the formation of a domain structure during annealing yielding high internal field and finally a long range field induced magnetic anisotropy [13]. It is worth noticing that this effect is not observed with Finemet which is not contradictory. Indeed, the Fe-Si crystallites are in the superparamagnetic phase during annealing [14] whereas it is probably not the case for Co-doped alloy due to the high Curie point of Fe-Co-Si phase [15].

The coercive fields are also reported in Table I. It is to notice that there are no clear relationship between the magnitude of the anisotropy fields and the coercivity of different materials. For instance, the results obtained with Fe-Co based nanocrystalline alloys suggest that the coercivity is basically linked to the magnetization process (rotation or domain wall displacement) and weekly to the magnitude of induced anisotropy.

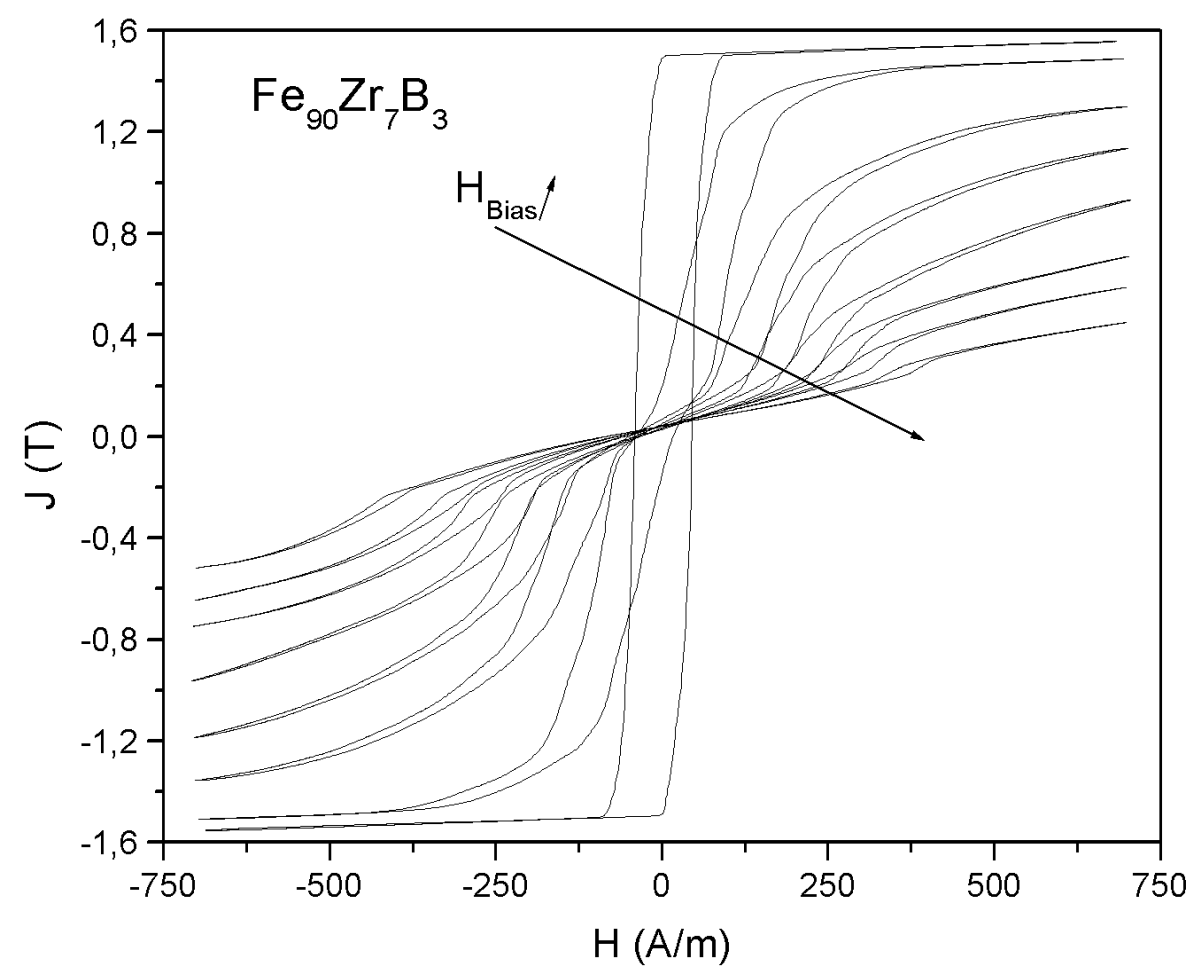

Figure 2: The shape of the hysteresis cycle as a function of increasing bias field

In conclusion, the approach of Weber [8] have been adapted to the determination of uniaxial magnetic anisotropy in anisotropic samples: the plot of $H_{S}=f\left(H_{B}\right)$ overcome the demagnetizing effect. This method allows for the first time to measure directly the longitudinal induced anisotropy in amorphous or nanocrystalline ribbons and wires. To the 


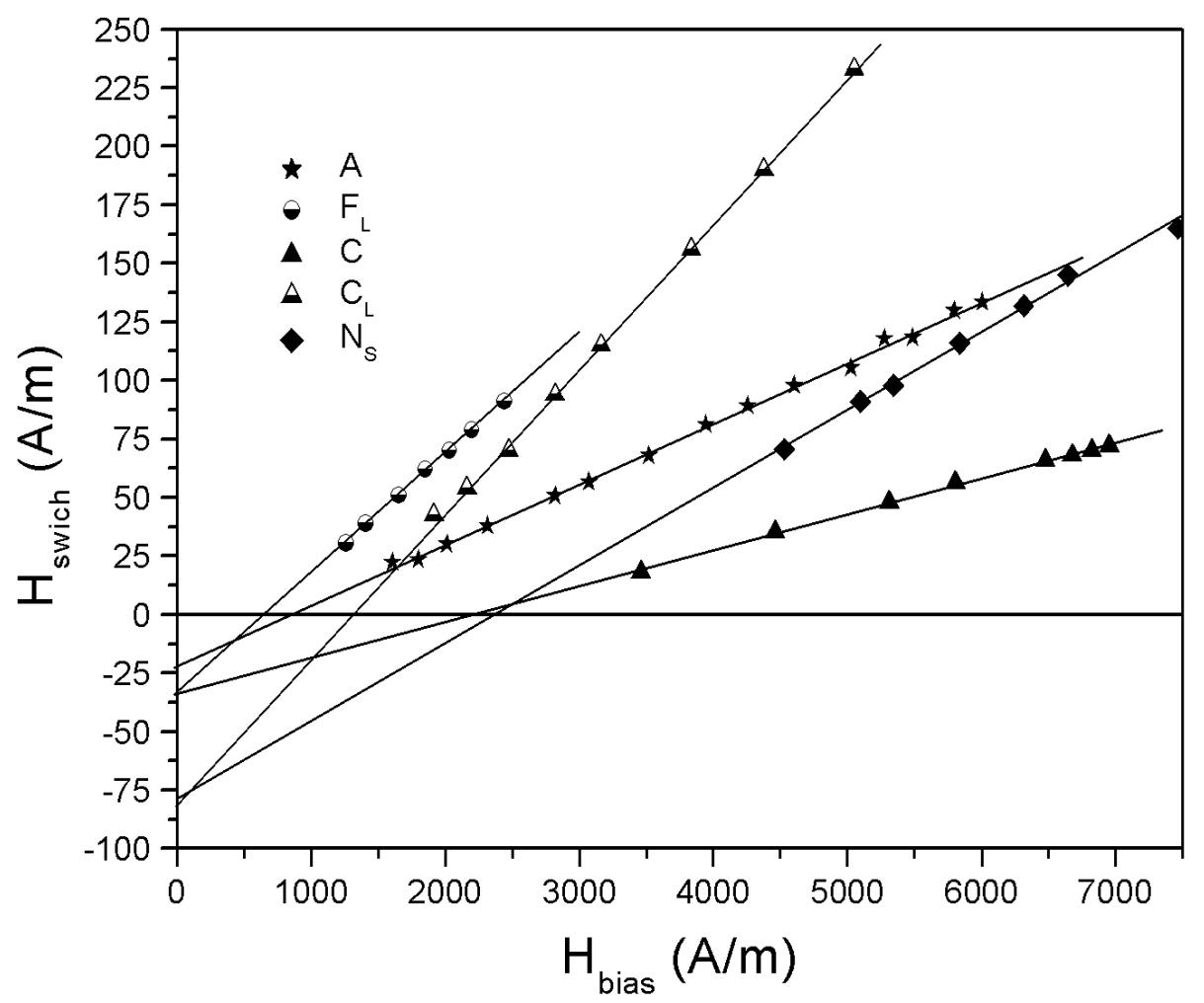

Figure 3: The switching fields plotted as a function of bias field. Extrapolation to $H_{B}=0$ yields $H_{K} / 2$.

authors' knowledge, evidence of self-induced anisotropy in nanocrystalline samples is also reported for the first time.

[1] Y. Yoshizawa, K. Yamauchi, IEEE Trans. Magn. 25 (1989) 3324-3326.

[2] G. Herzer, J. Magn. Magn. Mat. 133 (1994) 248-250.

[3] A. A. Glaser, N.M. Kleynerman, V. A. Lukshina, A.P. Patapov, V. V. Serikov, Phys. Met. Metal. 72 (1991) 53.

[4] L.K. Varga et al., J. Magn. Magn. Mat. 254-255 (2003), 477-479.

[5] G.Asti and S. Rinaldi, Phys. Rev. Lett. 28 (1972), 1584-1586

[6] J-M. Barandiaran, M. Vazquez, A. Hernando, J. Gonzalez, G. Rivero, IEEE Trans. Magn. 25 (1989) 3330.

[7] A. Garcia-Arribas, J.M. Barandiaran, G. Herzer, J. Appl. Phys. 71 (1992) 3047-49.

[8] W. Weber, R. Allenspach, A. Bischof, Appl. Phys. Lett. 70 (1997) 520-522. 
[9] F. Alves, P. Houée, M. Lécrivain, F. Mazaleyrat, J. Appl. Phys. 81 (1997) 8.

[10] G. Herzer, IEEE Trans Magn. 30, (1994) 4800

[11] Y. Yoshizawa, S. Fujii, D.H. Ping, M. Ohnuma, K.Hono, Scripta Mater. 48 (2003) 863-868.

[12] K. Suzuki, G. Herzer, J.M. Cadogan, Phys. Rev. B. 58 (1998) 2730.

[13] Idea suggested by G. Herzer, private communication.

[14] F. Mazaleyrat, J.C. Faugières, J.F. Rialland, J. Magn. Magn. Mat. 59 (1996) L33-L38.

[15] F. Mazaleyrat, Z. Gercsi, J. Ferenc, T. Kulik, L.K. Varga, Mat. Sci. Eng. A, in press. 